\title{
Equilibrium
}

Quarterly Journal of Economics and Economic Policy

VOLUME 8 ISSUE 3, 2013

ISSN 1689-765X, (Online) ISSN 2353-3293

http://www.equilibrium.umk.pl/

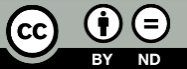

Held B. (2013), The Transformation of the Health Care Structure - Opportunity of Growth, "Equilibrium. Quarterly Journal of Economics and Economic Policy", Volume 8, Issue 3, pp. 27-47, DOI: http://dx.doi.org/10.12775/EQUIL.2013.018

\section{The Transformation of the Health Care Structure - Opportunity of Growth}

JEL Classification: $111,118,012 ; 014, P 46$

Keywords: healthcare regions, networks, scenario analysis, public governance, Germany

\begin{abstract}
The healthcare industry is a growth driver. However, the health system is facing a crisis, affected by the financial development in Europe. An almost completely regulated market is just as little use, as a largely deregulated market such as in the U.S.A. Both lead to gaps in the sustainable and comprehensive patient care. Based on the German Healthcare System, an analysis is performed. Currently, the German health care system is in a transformation process. Traditional forms of health care services provision and the existing governance system are coming to their limits. The current health care system no longer meets the requirements for ensuring accessible and affordable health care services. As new players on the German hospital market, commercial hospital groups have emerged. To get more informed on the effects at the regional level, a scenario analysis was performed. A trend scenario which shows a clear trend toward a substantial increase of regional imbalances was developed. On one hand, there are highly profitable regions with excellent medical service provision by commercial hospital groups, and on the other hand, there are peripheral regions with a second-rate medicine, which are left to the public sector. The paper derives first ideas about a new structure of the healthcare system for ensuring accessible and affordable health care services for the citizens.
\end{abstract}

(C) Copyright Institute of Economic Research \& Polish Economic Society Branch in Torun Date of submission: February 22, 2013; date of acceptance: May 28, 2013

* Contact: baerbel.held@stw.de, Steinbeis-Hochschule Berlin, Institute of Economics, 10247 Berlin, Gürtelstraße 29a/30, Germany 
The paper shows first ideas about the transformation of healthcare as an opportunity for growth.

\section{Introduction}

The healthcare industry is a growth driver not only in Germany. However, the health system is facing a crisis, affected by the financial development in Europe.

An almost completely regulated market such as the healthcare in the UK is just of as little use, as a largely deregulated market such as the one in the U.S.A.. They both lead to gaps in the sustainable and comprehensive patient care. Only a mix of socially balanced, but also market and competitive environment, creates a relevant optimum (Goldschmidt, Hilbert 2009, pp. 9-20). Germany has tried this, but failed. How does the current system do? What kind of impact does the current structure of health care have? What factors influence the success of health care? What trends can be expected? What conclusions can be drawn from this?

The health care sector is a political field which is highly relevant to citizens, and therefore to the political sector and its representatives. The current political discussions in Germany are marked by tensions between the concepts of solidarity and individual responsibility, by the questions of how costs can be reduced in the health care sector and how responsibilities for financing hospital infrastructures can be shifted away from public authorities. Demographic trends and the medical and technical progress are a constant threat for the financial sustainability of German statutory health insurances (SHI). The question of how the investment backlog in the hospital sector can be resolved and the optimum benefits for health care can be achieved with very limited financial resources remains unanswered. Not so much different from many other OECD-countries the German health care sector faces the following challenges:

Increase in expenditure: Medical and technical progress has significantly expanded supply in all areas (prevention, diagnostics, treatment, rehabilitation). The investment and modernisation backlog at hospitals is considerable. Hospital finance continues to be structured dualistically. The German federal states bear, to a declining extent, the costs of investments in the hospital sector. Hospital investment financing has declined by more than $44 \%$ in the past twenty years. The result is an investment backlog of approximately EUR 50 billion (Prognos 2007, p. 24).

Limitation of financials inflows: Fewer, but longer-living insured people (demographics) and political budget regulation limit the financial inflows into the health care system (Deutsche Bundesbank 2010). 
Efficiency of the system: The overall (fragmented) health care is not as efficient as it could be due to the current governance system. None of the fragmented players is in the position to bring the full potential of top medical research, education and medical technology to the patients, in order to fully exploit the benefits of an integrated health care provision.

Outcome of the health care system: The outcome of the German health care system is rather average compared to other countries, e.g. according to the OECD benchmark (OECD 2009). On an international scale, Germany is rated medium to low in terms of quality and efficiency (Blankart et al. 2009, p. 5).

An overall issue arising from challenges within the German health care sector is how the system structures, coordination tools and incentive mechanisms must be organised in order to fulfil a commitment to the citizens of a high quality, affordable service provision, while at the same time set incentives for increasing the efficiency and effectiveness of health care provision.

To react to these challenges, the German health care sector is in a substantial transformation process. For gaining a more informed insight at the effects on the regional level, a scenario analysis as a method of strategic foresight is performed. This results in a trend scenario for the service structure in a health care region. The following specific research questions are addressed:

1. What factors impact the structures of the health care sector?

2. What trends can be expected for the health care sector?

3. What conclusions can be drawn from this?

A comprehensive scenario analysis of the health care sector in Germany as presented here, has not previously been carried out in Germany. The analysis is based on original data, which was obtained from a combination of different research approaches, among them extensive interviews with experts, extensive documentary analyses and an academic monitoring in hospitals under various ownership. The aim is to get a more informed insight into the trends and the resulting impacts on the structure and the governance of the healthcare system in Germany.

In the next section, the research methodology will be described. Subsequently, in section 3, the results of the scenario analysis will be presented. The results will then be discussed, the impacts assessed and an ideal scenario for structuring a sustainable health care system is proposed. The article concludes with a summary and by identifying directions of further research. 


\section{Research Methodology}

The starting point for the study was literature research on forward-looking methods and scenario analyses. The identification of a suitable procedure from the many scenario methods was used as input for the resulting scenario analysis in the health care region chosen. These technique provide the methodological basis of the research.

The paper is based on a qualitative research design. A combination of different research processes (database research, library research, general internet research, contact to appropriate institutions, interviews with experts, collecting print materials, literature evaluation, academic monitoring) was employed for designing and carrying out a scenario analysis for a health region.

The paper's theoretical approach is based on a study of the literature on New Public Management (NPM). The study also takes into account the basic assumption of the public governance approach (Reichard 2002). Trends from New Public Management are: the tendency towards a reduction of the state to its core functions by redefining levels of public service provision, privatizing marketable sub-areas, and encouraging devolution process. The reorganisation of operational structures according to managerial principles, a strong commitment to de-bureaucratisation, agencification and a reduction of hierarchies (Gohl 2001) are also classical elements of the NPM reform agenda.

Furthermore, the ideas of the new institutional economics, specifically the theories to explain decision-making behaviour in politics and administration are drawn on, i.e. public choice theory, property rights theory and principal agent theory. Attention is also paid to the global trend towards hybrid organisational forms (Picot et al. 2003, etc.). Literature on the German health care sector and health care management (Busse, Riesberg 2005; Busse et al. 2010), in particular publications on case management, integrated health care provision (Salfeld et al. 2010), and studies focussing on the trends in the German health care sector in general (Kartte 2010; PWC 2009; Schmidt 2010) is referred to.

The documentary analysis for the health care region included an analysis by Price Waterhouse Coopers (2009), the current public annual reports of various private hospital operators (Rhön-Kliniken AG, Helios-Kliniken $\mathrm{GmbH}$, Sana-Kliniken AG), the annual reports of four different university hospitals and the published quality reports of the hospitals. The author also included the consolidated balance sheets and management reports of five other hospitals. 
The author participated as a scientific observer in the meetings of the hospitals. As a basis for evaluating the collected documents served the forecast model for hospital functionality (developed by the TU Dresden and KPMG (Arnold 2009)).

\section{Scenario Analysis as the Research Technique Employed}

In the academic Word, there are various methods or techniques aiming at providing a systematic and structured view of the future. Opaschowski, describes the role of future research as follows: "Future research must recognise looking ahead as a precaution. Looking ahead means planning and structuring events before they happen. Looking ahead should encourage action. Such research into courses of action and their consequences can be more important than the accuracy of some forecasts. Politics, economy and society are challenged to act and react" (Opaschowski 2009, p.19).

Scenario analysis as a sub-segment of future research is not a new concept. Transferring the term "scenario" into the economic and social sciences is attributed to Kahn und Wiener (1967), who developed the first method of generating scenarios with "scenario writing" in the 1960s and established the first definition (Kahn,Wiener 1967, p. 6). The method of scenario analysis is both a method of future research and of strategic management. As part of their decision-making processes, companies increasingly encounter uncertain and complex problem in areas of great strategic importance. Against this backdrop, systematically generated future alternatives - so-called scenarios - are gaining significance. More important than simply establishing these scenarios is thinking in scenarios and being prepared to act on the basis of alternative scenarios. Both of these are based on three principles (Fink et al. 2011):

- Future-oriented thinking and action: Recognizing a wealth of uncertainties and taking them into account in the decision-making process.

- Joined-up thinking and action: Recognizing and analyzing complex systems and making them manageable.

- Strategic thinking and action: Recognizing future earnings potential and developing and implementing visionary strategies to leverage this.

The scenario analysis methodology is used in the following, to undertake a trend projection for a health care region in Germany. 


\section{Application of the Scenario Analysis}

With respect to the phases of a scenario analysis, one finds in the literature different phase models which differ only slightly from one another. In our study, the phase model of Bishop et al. (2007) was employed. The following figure shows the steps of the analysis.

Figure 1. Steps of the scenario analysis

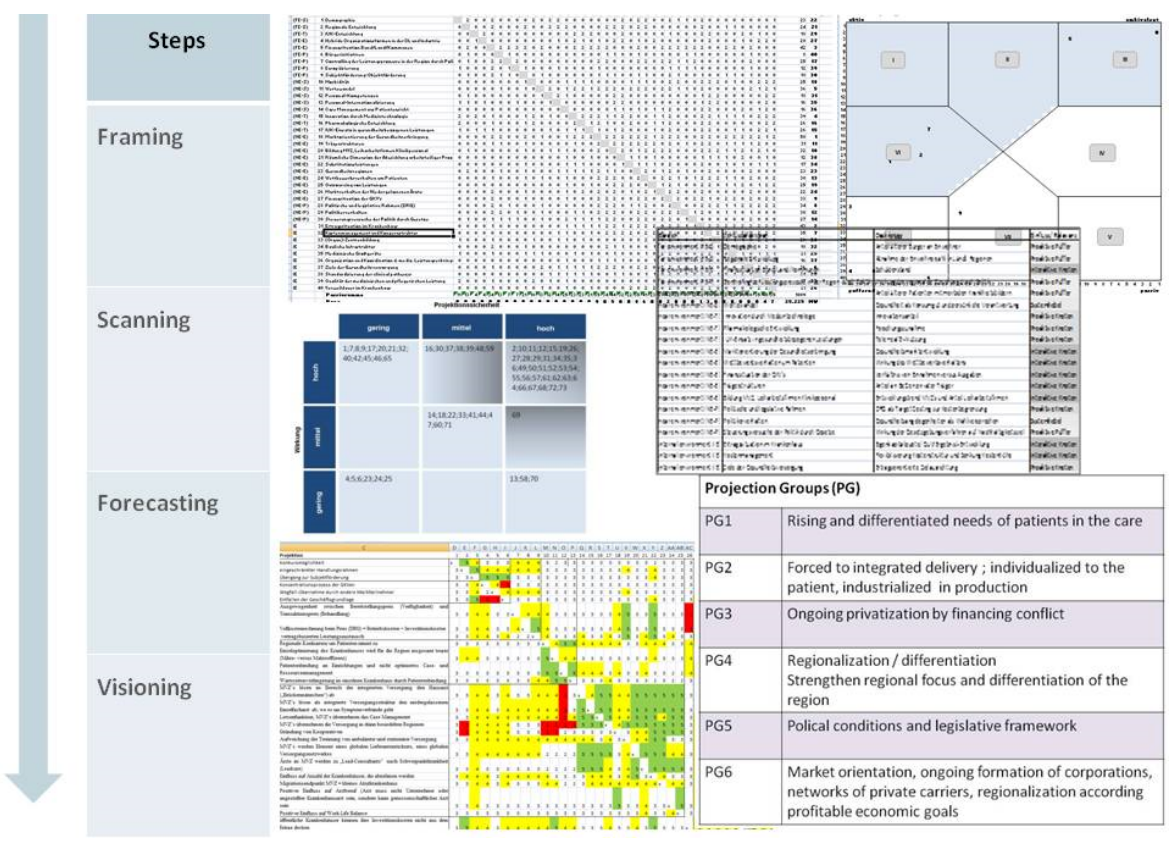

Source: own research.

In the first phase (Framing) the focus is on the analysis of the problem and tasks. In our case study, the scenario development started with determining the scope of the study, establishing the future horizon and setting the regional focus.

The second phase (Scanning) can be described as systematic selection and analysis of relevant key factors. At first, the major areas of influence in the scenario field are identified. The areas of influence are organised in our study according to the "Three Environments Model" (see Stapleton et al. 2000). The influence factors were determined in our study by a team of experts using the Delphi Method. Influence factors describe the specific forces in the scenario field. In the study, 40 influence factors have been identified 
by the experts. In the next step, the interplays and the relevance of the individual influence factors were regarded more closely in a networking analysis. The Figure 2 shows the Influence Matrix as entanglement.

Figure 2. Influence Matrix

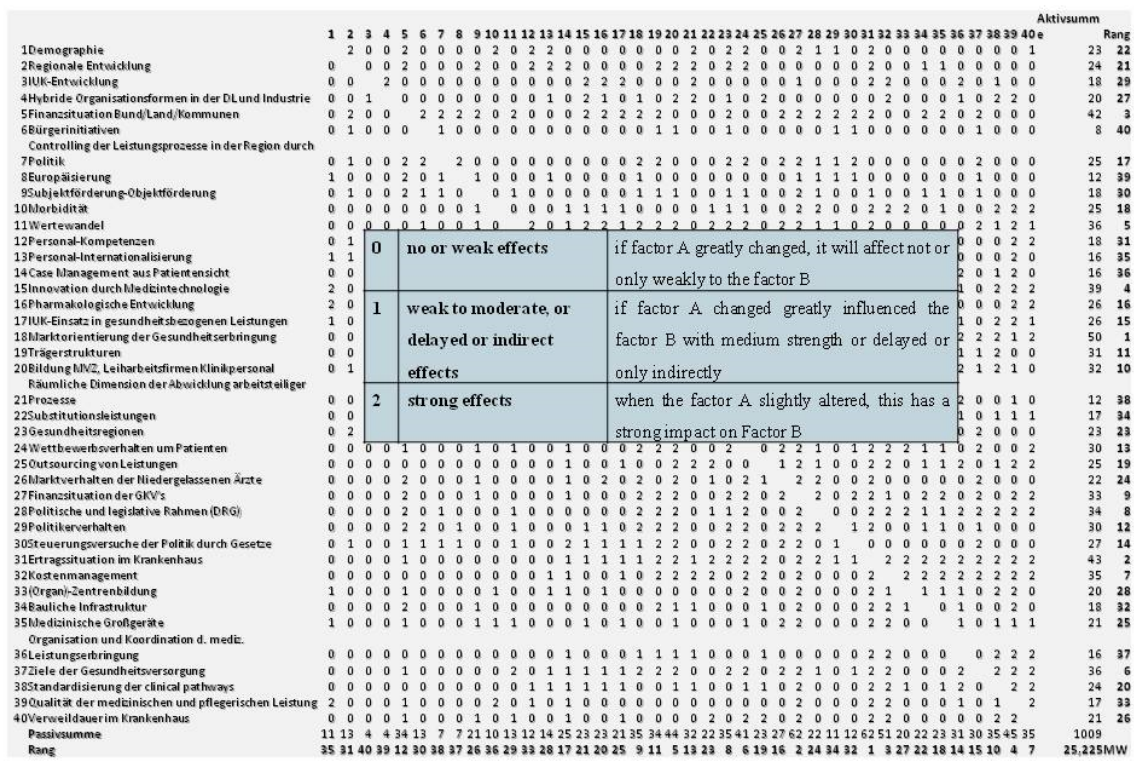

Source: own research.

For this step, an expert's work shop was conducted. The factors were presented in a system grid (active/passive grid). As a result, the 40 influence factors identified at the beginning could be reduced to 20 key factors. In a further workshop, the individual trends were projected into the future and discussed each by each.

In the third phase (Forecasting), the trend projections and scenario construction were derived and tested for their consistency. You see that in Figure 3. 
Figure 3. Consistency Matrix

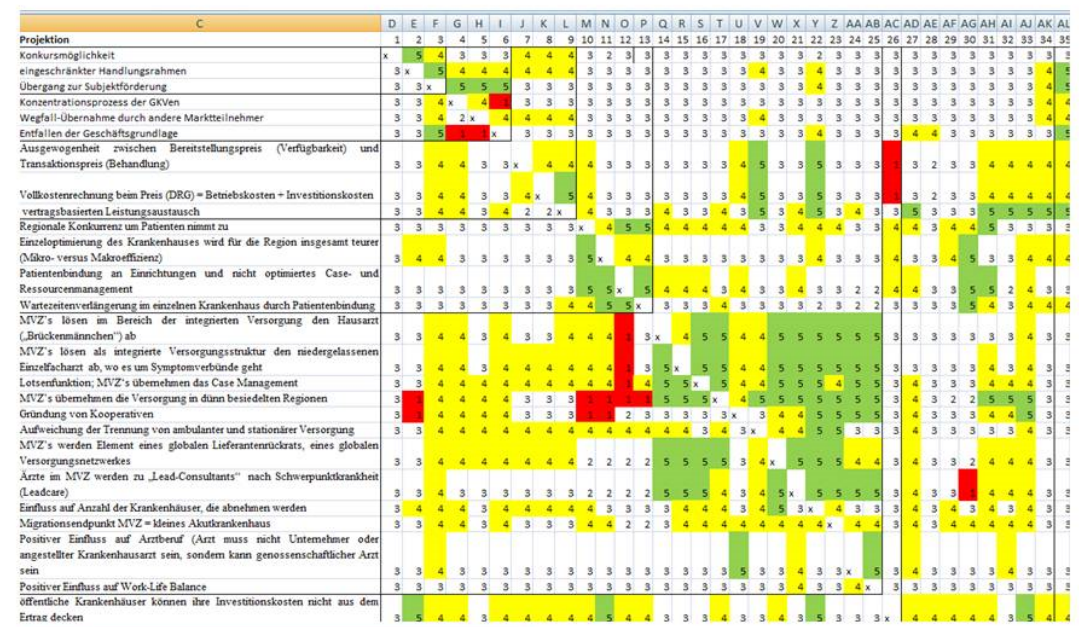

\begin{tabular}{|l|l|}
\hline 1 & total inconsistency \\
\hline 2 & partial inconsistency \\
\hline 3 & neutral or independent \\
\hline 4 & reciprocal beneficiaries \\
\hline 5 & strong mutual support \\
\hline
\end{tabular}

Source: own research.

A Consistency Matrix was used to form projection pairs, which in turn were compiled into projection bundles. Subsequently the projection bundles were combined into projection groups which were the basis for the raw scenario. Based on the projection groups a detailed trend scenario was developed.

The fourth phase (Visioning) analyses the scenarios and their interaction, interprets and evaluates them and derives recommendations for action which are then implemented in the Acting phase.

This publication only contains a selection of the results of the research project. I refer to the publications of the research project (Held 2012).

\section{Result: Trend Scenario}

The team consisting of managing directors, scientists, doctors and industry representatives used the Delphi Method to identify forty influential factors, which were then analysed in an influence matrix with regard to their integration and relevance. A total of 42 interviews were conducted in person and by 
telephone as part of the expert survey. The outcome is a system grid from which the twenty relevant key factors can be selected. To this end a workshop was conducted with the experts. Methodologically, this procedure is based on Fink et al. (2011), who developed this process for companies. The authors therefore adapted the methods for use at macro level.

The potential future status of each relevant key factor as a trend was then determined and described. The trends were analysed and described and the projections for the future drawn up under intensive evaluation of the studies, the literature, databases, interviews and in the form of scientific monitoring. Two workshops were conducted with the experts to determine the key factors and to describe the trend projections. As part of the academic monitoring, the author worked in four hospitals under different ownership in the period from February 2011 to May 2012; in this capacity she conducted over 23 meetings took part in certification procedures, carried out over 56 interviews with doctors, nurses, patients, hospital directors and the administration and helped on the ward.

Figure 4. Projection Groups

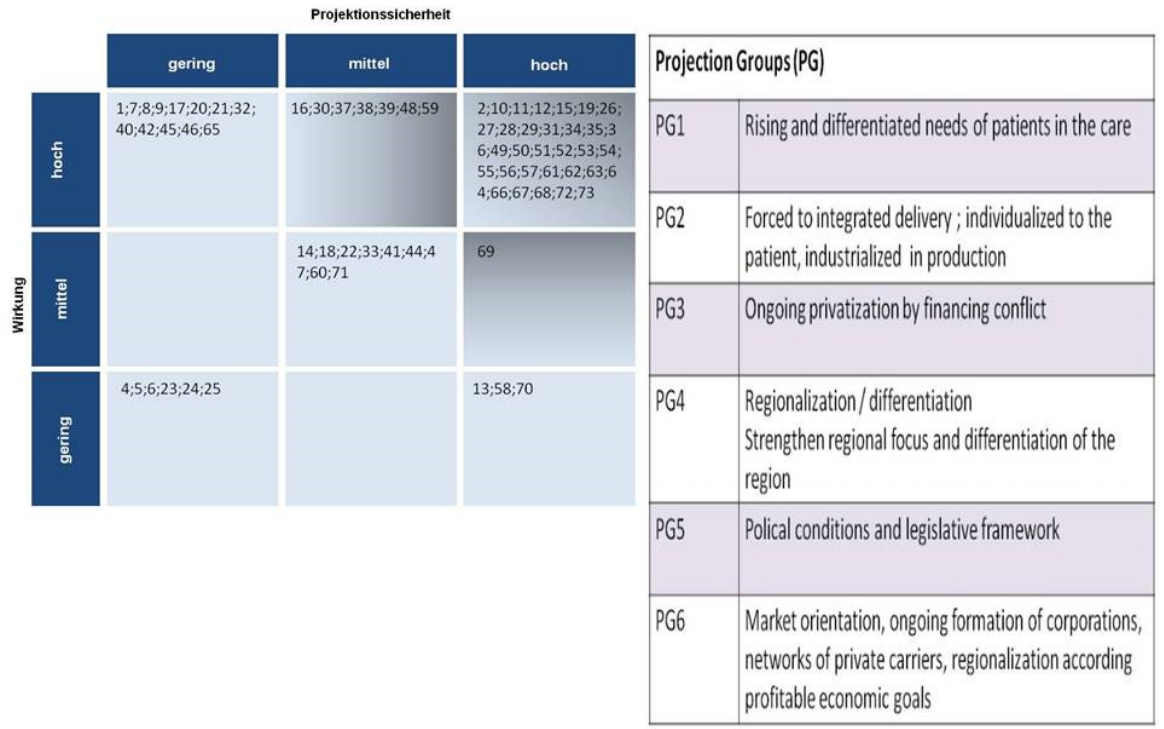

Source: own research. 
Each trend that is analysed and described is projected into the future. Using the consistency matrix, of 73 projections determined, 5329 projection pairs are analysed to identify whether these pairs are mutually exclusive or complement each other. All the projection bundles marked as "Mutually dependent" or "Support each other" in the consistency matrix are subsequently checked in terms of projection certainty and the impact of the projection pairs. A three-point scale was used here, from low, through medium, to high impact, along with a three-point scale for projection certainty, from low, through medium, to high. The outcome is projection pairs, resulting in a list of consistent projection bundles, with which the future area can be described to the greatest possible extent. The projection bundles were combined into project groups (PG) in the scenario analysis. The following is referred to as the projection bundle catalogue and includes the raw scenarios.

Figure 5. Basic Principle of Industrialisation

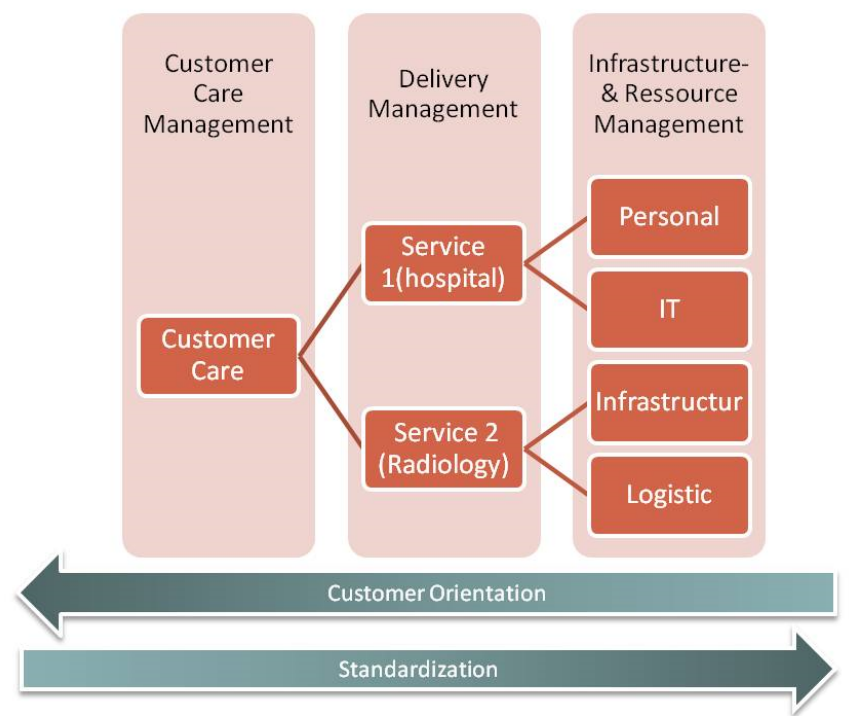

Source: own research.

As a result, a scenario is identified from the projection groups as a trend scenario. This scenario describes the ongoing increase of regionalised, commercially-oriented health care structures (networks), which will replace the independence of individual hospitals. Private hospital owners are combating the increasing requirement for integrated, individualised health care, accom- 
panied by rising cost and innovation pressures, by forming groups and networks and creating industrial service structures.

Service provision is industrially graduated according to regional services (patient management, case management, out-patient care, partner management), and organised supra-regionally in shared services or externally provided services (diagnosis, treatment, rehabilitation). Resource management (staff, infrastructure) based on the global sourcing approach is rendered flexible and acts according to traditional service management principles. The figure illustrates the basic principle.

Figure 6. Essentials of the Scenario

\begin{tabular}{|c|c|}
\hline & Scenario \\
\hline Governance & Public Governance Framework \\
\hline Shareholder & $\begin{array}{l}\text { private dominated } \\
\text { publicislands }\end{array}$ \\
\hline Regional Entrepreneur & Private Healthcare Companies \\
\hline Social Sponsorship & subject \\
\hline Regional Strategy & $\begin{array}{l}\text { most attractive regions } \\
\text { public: obligatory provider in non-attractive islands }\end{array}$ \\
\hline Structure & $\begin{array}{c}\text { Regions with managed, standardized healthcare services } \\
\text { "classic“ islands (manufactories-hospitals) }\end{array}$ \\
\hline Service Structure & $\begin{array}{l}\text { Regional Management } \\
\text { Case-/ Patient Management } \\
\text { Delivery Management } \\
\text { Resource Management } \\
\text { Innovation Management }\end{array}$ \\
\hline \multirow[t]{2}{*}{ Quality } & significant differences between regions and islands \\
\hline & Regulated Market \\
\hline Possible disadvantages & $\begin{array}{c}\text { monopoly no competition/ Pricing is not on the market / } \\
\text { health care is expensive/ Investing only in profitable } \\
\text { locations Recovery yield without reinvestment Efficiency on } \\
\text { the basis of wage costs }\end{array}$ \\
\hline
\end{tabular}

Source: own research.

The private health care providers in the emerging regional structures act as integrated maximum providers in regions. Regional selection is made according to commercial principles with a view to earnings optimisation. Investment in unattractive regions is prohibited. The strategic use of regionalisation by private owners as an element of business area development takes the existing competition between the public sector and private hospital structures to a new level. After assuming cost leadership by systematically using 
economies of scale and flexible cost measures, the private hospitals will also aim to become the quality leaders. The focus is not on the quality of treatment in individual cases, but on holistic, integrated and managed patient care as a distinguishing feature, setting them apart from the local authority hospitals. The next figure shows a summary of the scenario essentials.

\section{Discussion of Results and Policy Implications}

In the following, the impacts the trend scenario will have at meso level will be presented in summary form. Subsequently, a new solution for the composition of health care regions, as a result of the impact analysis, will be presented for discussion.

The environmental factors analysed the impact of both of the groups investigated, hospitals under public sector and private ownership, so to speak. This also includes the underlying political situation. The core issue is how hospital owners deal with the environmental conditions and requirements. It is exactly this situation in which a supra-regional owner chooses the crossregional strategic approach, while the local owner in the end remains trapped in their local approach. The surviving hospitals under private sector ownership can only counter these industrially organised, commercial health care regions with local structures, which despite some excellent managers and even in small regional associations, cannot achieve either the cost-cutting or quality effects of the supra-regional, private groups. Competition for patients remains the local stumbling block which cannot be eradicated. The public sector will have to meet its health care service mandate in unattractive regions with high (additional) financial outlay. The quality of health care services will finally become second-rate, as such local emergency structures are neither attractive for specialists, nor can they ensure the opportunities of innovative medicine: integrated, individualised, affordable health care, in the long term.

Notwithstanding individual, dedicated hospital management and local authority administration, the continuing privatisation of formerly public sector hospitals will be accepted by the public authorities. It is part of the increasing inability to act resulting from the high debts of the public coffers. In particular with regard to local authorities, the sluggish introduction, and especially the application of double-entry accounting, rendering the decline in the value of capital goods visible, is a perfect example of the local authorities' behaviour as a hospital owner. The passive attitude of the local authority owners ultimately leads to privatisation of health care structures increasing. The creation of monopolies, and therefore unlimited price increases for health care services, pose the greatest danger from an economic perspective. 
The greatest risks if the scenario were to occur are summarized below: second-rate medical treatment, under-supplied regions, characterized by a lack of doctors, long distances to hospitals, poor local service provision in these peripheral regions with expensive health care services. Modern, highperformance medicine does not reach these regions, the knowledge and research transfer takes far too long. A sustainable health care system cannot be established in all parts of the country.

Therefore, there is no question that the public sector or society can reverse these trends. None of the requisite key factors shows a respective trend which would allow such a projection - strong public sector hospital.

The question to be answered now is rather under what assumptions the public sector can lose the ownership of the hospitals, but still retain a significant role (public governance), in the interests of citizens and patients, in ensuring the health of the citizens as a duty of the public sector, if services are provided by the private sector.

Solutions in answer to this question can be developed by analysing the impact of trend projections for the stakeholders, from deliberations in the discussion groups and expert talks and by using theories on governance approaches, from which specific options for action must be derived.

As a result, a second scenario was developed as a so-called ideal scenario. The objective of this is to guarantee every citizen in every region an efficient, integrated health care system in accordance with previously defined, uniform service standards, of high quality, which are affordable for every citizen.

It was ascertained from the results of the trends analysis that health care provision is increasingly becoming an entrepreneurial function involving the assumption of risk and the necessity of innovation. The more entrepreneurial tasks it is faced with, the less the state is in a position to deal with them. Luhmann (1971) recognized that types of systemic structures provide the preconditions in decision-making. Here, systemic structures represent the operating programs as conditional or intended programs, the organizational structure as coordinating in the extreme situation between hierarchy and market, and thirdly, the employees. The resulting thesis maintains that structures pertaining to the health sector, more concretely in the field of hospitals, are inadequate when it comes to coping with the stated challenges.

No tool is more efficient than the market when it comes to generating efficiency within a localised object. With regard to managing and designing an entire system (health care system) with sustainability objectives, however, the market alone is a useless tool. In the market tool, elements such as social aspects (justice, equal opportunities for everyone) and ecology itself (conserving resources at the price of not gaining an economic benefit) are excluded. The market tool does not promote effectiveness, which does not exist 
from the market point of view, as there is no interest in the sense and benefit of the products, but only whether they can be realized on the market. The market tool does not in itself contain any moral fibre. This can only be demanded by the market players. Morals require values and standards which are in turn shaped by the system of society as a whole. The same applies to the values and behaviour of the entrepreneurs on the market. In designing the structures of the health care sector, however, the goal is to find a common denominator for all three aspects of sustainability, i.e. economy, social issues and ecology. This means dissolving the tension between ensuring the market as a tool to optimise economic efficiency and at the same time creating a sensible situation with regard to impact and benefit for the entire society. This may be achieved using the tool of hierarchy. One example of this is the control of the pharmaceutical industry in medicine production. The ideal scenario for the health care sector, therefore, includes the approach of combining both tools, the market and hierarchy, with each other, as outlined in the following figure.

Figure 7. Template Scenario II

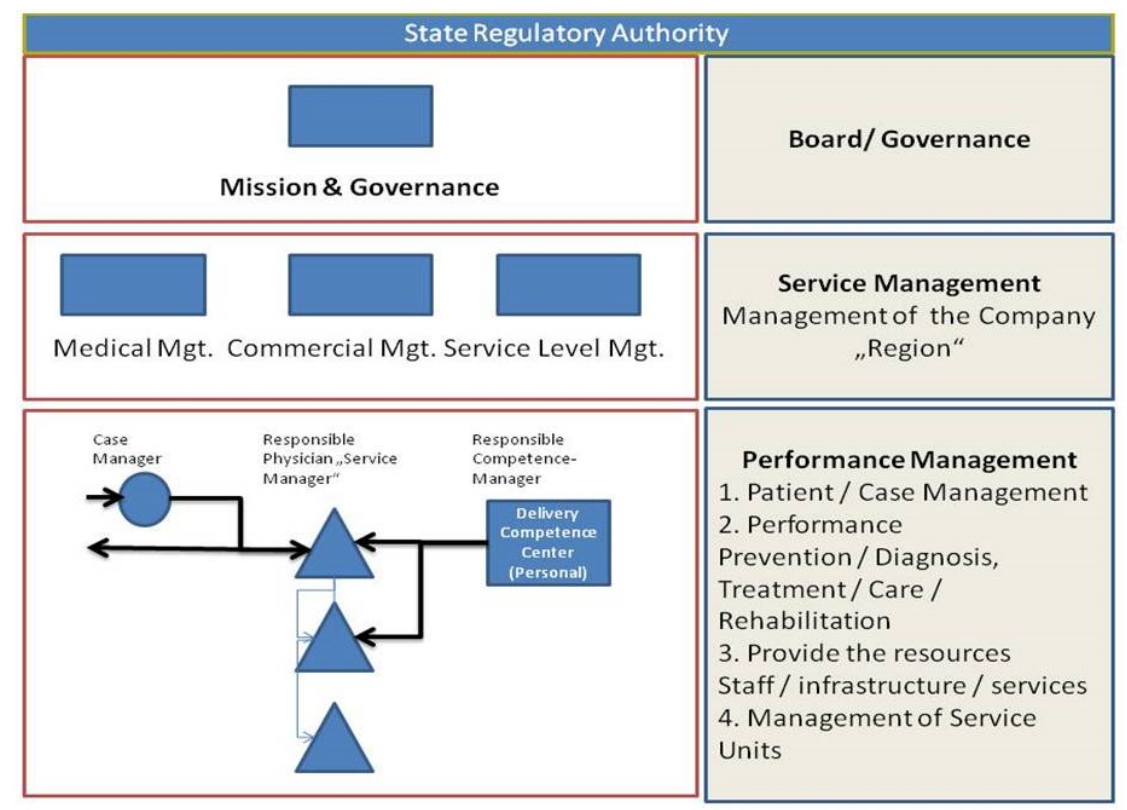

Source: own research. 
The model methodically follows the theories on governance approaches. Large parts of the economy no longer correspond to a corporate model in which companies are regarded as complete, integrated structures. Modular organisations, networks and cooperation networks, electronic markets, telecooperations and virtual organisational structures are already a reality. Local, modular-segmented structures, characterised by autonomy, cooperation and indirect management, are increasingly taking the place of corporate hierarchies which primarily function by order and obedience.

This development is directly related to the situation in the sector in the form of far-reaching changes in the competitive environment. Product, labour and information markets are becoming increasingly globalised, the innovation potential of information and communication technology and new innovation strategies, as well as the value shift in the world of work and society, pose new challenges for companies, which must react with new organisational forms. The market process theory and new economy of institutions are important reference theories in this area. This approach focuses on the economic governance approach, if governance is understood to mean the internal management forms of companies, as a concept which describes the criteria of performance and control, illustrates how the activities of various organisational units are coordinated with each other and how an organisation's relationships with external players are structured (Picot et al. 2003). The research interest of economic governance approaches lies in analysing institutional arrangements from an efficiency perspective. It is endeavoured to identify governance structures which generate the lowest possible transaction costs under the given environmental conditions (Ebers, Gotsch 1995, p. 199). The transaction cost theory (Coase, Williamson, Picot), the property right approach (Coase, Alchian, Demsetz, Picot), and the principal-agent approach (Jensen, Meckling) can also be included in the economic governance approach. The concept of public governance has also been incorporated into the model. However, it no longer applies solely to the new public management concept in the narrower sense, i.e. the focus on the internal structure, but it strives for a broader analysis and design approach: effective public sector structures plus a civil society and market-based solution (Reichard 2001, p. 3), and is accordingly related to the concept of the state as a guarantor and new institutional economics.

Three levels are assumed in the model. Public governance occurs in the form of a government regulatory authority, which has a hierarchy and is therefore equipped with positional authority and the means of sanction and reward, in order to control and monitor service provision in the health care sector and define rules for the health care market. To this end, the authority can set up independent institutions, which, for example, set down the service corridors to be provided and evaluate the benefit and effectiveness of ser- 
vices and products. In addition to monitoring the quality of performance, service and economic efficiency for the citizens/patients must be monitored and regulated, for which it is necessary to define appropriate service offerings for the citizens/patients in the form of levels, as well as quality standards, and to monitor service providers' compliance with them, imposing negative sanctions if applicable (e.g. withdrawing the business permit).

Below the regulatory authorities, the health care region will not be determined according to political calculations, but according to commercial aspects such as the number of inhabitants, age, morbidity levels, etc. or will be formed pursuant to these criteria and awarded a Supervisory Board for the health care region. The latter formulates the shareholder agreements, establishes an appropriate audit committee, anchors the public corporate governance code in the contract and introduces performance controlling.

The Supervisory Board, which is comprised of representatives of the health insurance company, citizens' representatives from the local authorities, the federal state, etc., is personalised and also bears personal responsibility. The Supervisory Board has the opportunity to call for tender for provision of specific services for a health care region and may permit bids from various service providers which can compete on quality and price. The Supervisory Board bears the overall responsibility for ensuring the quality and economic efficiency of the health care region. It is also responsible for fulfilling strategic objectives.

Below the Supervisory Board level, the health care region company can be allocated in accordance with the legal provisions pursuant to the principle of subsidiarity. This company can be managed by either a private company, a cooperative or an institution under joint ownership. This company will establish itself as a network. The complete management of medical service provision (medical management), commercial management and service management are the company's main tasks. Strategies for the entire company and the implementation and control mechanisms are established, coordinated and managed here.

In addition to this overall service level, management is responsible for providing operational services in customer care, delivery and resource management.

In accordance with this model, the service mandate and service provision are separated in line with the idea of the state as guarantor. 


\section{Conclusions}

The methodology of scenario analysis has been used in this way for the first time to undertake a current trend projection on the health care sector in Germany. Scenario analysis has certain limitations.

The scenario analysis method is very complex and despite this, cannot guarantee certain results or provide specific probabilities. This is the most important methodical limitation. Furthermore, the answers from the experts surveyed and the stakeholder representatives only ever portray an excerpt of the objective reality, often being subjectively influenced. However, the results of the scenario analysis on the health care sector revealed potential and highly probable trends in their diversity, in their positive and negative impacts for all those affected, and they can now be publicly discussed. The strength of the scenario analysis lies mainly in increasing awareness with regard to the interaction between impacts on the object in question and its environment. The article focused on the issue of which factors influence the structures in the health care sector, the trends and their development, as well as questions on the scenario analysis method if it is raised from the company level to the meso level. Furthermore, the impacts and the options for action to be derived are evaluated. It was possible to analyse which 20 factors impact the structures of the health care region. It thereby became clear that the health care system in its current structure is unable to counter increasing requirements for integrated, individualised health care for patients, accompanied by rising costs and innovation pressure. The trend towards privatisation in the health care sector is irreversible, mainly due to the public sector finance situation. It is not possible to pump enough additional finance into the system, since today's high debt and the resulting changes introduced to the constitution (debt cap) and Basel III do not permit any further loans to be taken out.

Scenario technology and the discussion among experts enabled the trends in the health care sector to be determined. The trend scenario developed describes an ongoing increase in regionalised, commercially-oriented health care structures (networks). The managed, commercial region, released from stiff administrative limits, will be more efficient than isolated operations or loose network associations. It is the only organisational form which will be able to provide a service pledge to customers and their health insurance company and therefore be an attractive partner (in competition with other regions). Industrialisation will force focussing (focus on customers, performance and resources) and specialisation in service provision. Private health care providers will, however, select health care regions in accordance with efficiency criteria and the lack of investment in unattractive regions will have consequences for citizens and patients. Unmanaged privatisation bears 
the risk that monopolies will be created, pricing policy will be unregulated and therefore the health care system will become more expensive, resulting in second rate medical care.

Solutions for structuring the health care sector could then be derived in the form of an "ideal scenario". Accordingly, German federal states and local authorities, in cooperation with the health insurance funds, face the task of finding their new role, not primarily as the owner of individual service providers but in regional management as public governance. The focus of the government's (federal states and local authorities) tasks is no longer on hospital operation, according to the trend scenario above. Although they remain key elements of an integrated health care system, they can only survive if they are embedded in a highly efficient, industrialised service landscape. According to the new scenario, ensuring the provision of services in modern health care management now means governance, regional management, education and research. Governance thereby specifically means establishing and monitoring standards and services of the health care region by the public sector; regional management, commercial operation of the health care region in interaction with other local authority services, is, however, no longer the operational responsibility of the public sector.

The abolition of the current regional health care structure, which is based on political regions, the establishment and design of new health care regions from a commercial and health care policy point of view, the abolition of the planned economy for the health care sector in the form of the number of beds, the size of hospitals, price setting for health care services and the establishment of the health care service mandate per hospital, the creation of real market conditions in which a patient is actually a customer for the service provider, etc. and the "release" of the local authority hospitals, still managed as legally dependent entities, into the market at the same time as state governance are possibilities which are being discussed in a broader societal context and will have to be supported by science and practice. Separating the design of health care structures from politically motivated health care offerings structured for election tactics and electoral purposes, and introducing structures which entail personal liability, assumption of responsibility, risk assumption and responsibility, would be a further imperative to sustainably reform the health care sector.

The question therefore to be answered in future research is under what assumptions and by what means the public sector can lose the ownership of the hospitals but still retain a significant role, in the interests of citizens and patients, in ensuring the health of the citizens as a duty of the public sector. This research then focuses firstly on the transformation process that most hospitals must undergo with regard to their system shift towards integrated, industrialised service provision if they want to survive on the market and 
solve their efficiency and effectiveness problem. Secondly, there is a need for clarification regarding the government's, the federal state's and the local authorities' changed responsibilities and duties in light of the emerging governance of the "integrated, customer-oriented health care region undertaking", as described in the ideal scenario.

In order to derive options for action and measures to implement this new role for government, politics and its administration, the following strategic complexes must be further dealt with by researchers:

- Combination of competition and hierarchy (hybrid) as a coordinating tool,

- Design of the strategic and operational coordination in the health care regions,

- Design of the incentive structures and research into the driving forces for the players in the health care sector,

- Research into the social motives for action, values, ethics and stakeholders' morals,

- Development of a performance measurement system for management and regulation of the health care regions and to design a sustainable health care system.

The author believes that further research is required in the near future, primarily accompanying research into the transformation of specific regions and hospitals/hospital associations under public sector ownership and into supporting an adaptation of the management system for commercial health care regions from the industrial sector.

There are operational research requirements with regard to linking regional management with the issue of the commercial health region, particularly in terms of economic stability and the establishment of implementation options for the governance function of public leaders.

Furthermore, scientific support in evaluating the quality of medical care and developing medical innovation strength in regions, as well as the market and competition-oriented acknowledgement and evaluation of these developments, remains important.

\section{References}

Alchian A.A., Woodward S. (1988), Review: The Firm Is Dead; Long Live The Firm a Review of Oliver E. Williamson's The Economic Institutions of Capitalism, "Journal of Economic Literature", Vol. 26, No. 1.

Arnold C. (2009), Entwicklung eines strategischen Prognosemodells für Krankenhausunternehmen in Deutschland, Winter Industries, Köln.

Bishop P., Hines A., Collins T. (2007), The Current State of Scenario Development: An Overview of Techniques, "Foresight", Vol. 9, No. 1. 
Blankart C., Fasten E., Schwintowski H.-P. (2009), Das deutsche Gesundheitswesen zukunftsfähig gestalten, Springer. Berlin, Heidelberg, New York.

Busse R., Riesberg A. (2005), Gesundheitssysteme im Wandel, Medizinisch Wissenschaftliche Verlagsgesellschaft, Kopenhagen.

Busse R., Schreyogg J., Tiemann O. (2010), Management Im Gesundheitswesen, 2. Edition, Springer, Berlin, Heidelberg, New York.

Coase R. (1960), The Problem of Social Cost, "Journal of Law and Economics", Vol. 3, No.1.

Deutsche Bundesbank (2010), Finanzstabilitätsbericht 2010, online: http://www.bundesbank.de/download/volkswirtschaft/finanzstabilitaetsberichte/fi nanzstabilitaetsbericht2010.pdf (15.12.2011).

Ebers M., Gotsch W. (1995), Institutionenökonomische Theorien der Organisation [in:] Kieser A. (ed.), Organisationstheorien. 3., überarb, Auflage, StuttgartKohlhammer.

Fink A., Siebe A., Schlake O. (2011), Entwicklung, Bewertung und Nutzung von Zukunftsszenarien, online: http://www.scmi.de (08.08.2011).

Goldschmidt A.J.W., Hilbert J. (2009), Von der Last zur Chance - Der Paradigmenwechsel vom Gesundheitswesen zur Gesundheitswirtschaft [in:] Goldschmidt A.J.W., Hilbert J. (ed..), Gesundheitswirtschaft in Deutschland. Die Zukunftsbranche. Band 1 der Schriftenreihe: Gesundheitswirtschaft und Management, kma-Reader - Die Bibliothek für Manager. Wikom-Verlag (Thieme), Wegscheid.

Gohl C. (2001), Bürgergesellschaft als politische Zielperspektive [in:] Aus Politik und Zeitgeschichte, Beilage zu: Das Parlament; B 6-7 / 2001, Berlin. Ebenso auch in: Prozedurale Politik am Beispiel organisierter Dialoge, Münster, Hamburg, London.

Held B. (2012), Nachhaltiges Gesundheitswesen in Deutschland, Teil 1: Trends im Gesundheitswesen und deren Auswirkungen auf die Struktur der Gesundheitsversorgung unter Anwendung der Szenarioanalyse [in:] Held B. (ed.), New Public Management, Bd. 2, , Stuttgart.

Jensen M.C., Meckling W.H. (1976), Theory of the Firm: managerial Behavior, Agency Costs and Ownership Structure, "Journal of Financial Economics", Vol. 3, No. 4.

Kartte J., Neumann K. (2011), Weltweite Gesundheitswirtschaft-Chancen für Deutschland, Studie im Auftrag des Bundesministeriums für Wirtschaft und Technologie, Roland Berger-Strategy Consultants, online: http://www.roland berger.com/pressreleases, (15.01.2012).

Kahn H., Wiener A. (1967), The Year 2000: A Framework for Speculation on the Next Thirty- Three Years. New York.

Luhmann N. (1971), Politische Planung, Aufsätze zur Soziologie von Politik und Verwaltung, Opladen.

OECD (2009), Gesundheitsbericht 2009, Organisation for Economic Co-operation and Development (OECD), 8. Dezember.

Opaschowski H. (2009), Zukunft neu denken [in:] Popp R., Schull E. (ed.), Zukunftsforschung und Zukunftsgestaltung Beiträge aus Wissenschaft und Praxis. Berlin.

Picot A., Reichwald R., Wigand R.T. (2003),: Die grenzenlose Unternehmung, Gabler, Wiesbaden. 
Prognos A.G (2007), Trendstudie 2007: Gesundheitsbranche - Dynamisches Wachstum im Spannungsfeld von Innovation und Intervention, Deutsche Industriebank AG.

Price Waterhouse Coopers (2009), Krankenhaussektor Deutschland, Bestandsaufnahme, Situationsbericht der Krankenhäuser an Hand der Jahresabschlüsse bis 2008, 14. Mai.

Reichard C. (2001), Verwaltungsmodernisierung in Deutschland aus internationaler Perspektive [in:] Wallerath M. (ed.), Verwaltungserneuerung. Eine Zwischenbilanz der Modernisierung öffentlicher Verwaltungen, Baden-Baden, Nomos.

Reichard C. (2002), Governance öffentlicher Dienstleistungen [in:] Budaus D., Schauer R., Reichard, (ed.), Public und Nonprofit Management, Neuere Entwicklungen und aktuelle Problemfelder, Linz..

Salfeld R., Hehner S., Wichels R. (2009), Modernes KrankenhausmanagementKonzepte und Lösungen, 2. Edition, Springer. Berlin, Heidelberg, New York.

Schmidt H. (2010), Gesundheitsreport-Nachhaltigkeit, Büttelborn.

Stapletorn T. et al. (2000), Complexity and the External Environment, The Open University, Milton Keynes.

Williamson O.E (1998), Transaction Cost Economics: How It Works; Where It is Headed, "De Economist", Vol. 146, No. 1. 